\title{
Changes in Marketing Management Induced by the COVID-19 Pandemic: Lithuanian Organisations' Marketing Landscape
}

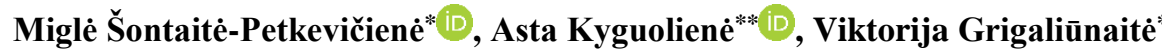

\begin{abstract}
The COVID-19 pandemic has affected all aspects of people's lives, politics, and business. The pandemic forced businesses to overlook their strategies including the marketing function. Therefore, the research aims to determine changes in organizations' marketing management that have been induced by the COVID-19 pandemic in Lithuania. To achieve the aim of the research the analysis and synthesis of scientific literature and questionnaire research have been applied. The analysis of the research results revealed that organisations increasingly take advantage of the benefits of e-commerce. Nevertheless, most of the organisations do not follow global recommendations not to decrease marketing or advertising budgets during the crisis, and it was especially evident during the first wave of the COVID19 pandemic. Moreover, the assumption could be made that the COVID-19 pandemic will accelerate the paradigm shift in a business-consumer relationship. The provided results are valuable for scientists as well as marketing practitioners. Insights provided in the research will enable organisations to react appropriately to the crisis and take necessary marketing actions. Moreover, the received results have indicated the changes which occurred in the marketing landscape. These findings create scientific value and provide a basis for further research.
\end{abstract}

Keywords: COVID-19; pandemic; crisis; marketing; marketing management.

JEL classification: M30, M31.

\section{INTRODUCTION}

In 2019 the world faced a pandemic crisis - COVID-19, which hit all the world strongly during 2020. In the middle of March 2021, the number of confirmed COVID-19 cases worldwide surpassed 120 million, including over 2.6 million deaths with still uncertainty of possible scenarios for 2021 (World Health Organization, 2021). The pandemic impacted not only health issues but also led to many outcomes in economics, regional stability, changed

\footnotetext{
Faculty of Economics and Management, Vytautas Magnus University, Lithuania; e-mail: migle.sontaitepetkeviciene@vdu.lt (corresponding author).

Faculty of Economics and Management, Vytautas Magnus University, Lithuania; e-mail: asta.kyguoliene@vdu.lt.

Faculty of Economics and Management, Vytautas Magnus University, Lithuania; e-mail: viktorija.grigaliunaite@vdu.lt.
} 
social life. It also had political and security consequences, disrupted education, mobility, tourism, sporting, and leisure (Qiu et al., 2017; Donthu and Gustafsson, 2020). New consumer behaviour and consumption patterns have arisen (Donthu and Gustafsson, 2020; Hoekstra and Leeflang, 2020; Nielsen, 2020). Distortion required both governments and business organisations to search for ways how to adjust to a still uncertain environment.

Unprecedentedly low, explosively high, or muted demand, depending on the category, distorted supply chains, transformed work, social distancing, and all these changes, including the lockdown, were the drivers, which forced businesses to overlook organisations' strategies. The marketing function, as one of the organisational functions, was affected by the pandemic as well. Marketing strategies required that they were adjusted to reach customers in a more water-life strategy rather than a red or blue ocean strategy (He and Harris, 2020). Due to the importance of marketing activities during the pandemic, companies faced the dilemma: to cut marketing and advertising budgets or to maintain, reallocate or maybe even increase them. Due to the lockdown, marketing channel redesign became a must in most of the countries (Hoekstra and Leeflang, 2020), i.e., organisations were bound not only to develop ecommerce, but were forced to look for multichannel options, last-mile delivery issues, and new supply chain management. Pricing policy became a matter of ethics, raising a dilemma whether to adjust to higher price sensitivity or to choose exploitative pricing strategies. The changed behaviour patterns forced companies to reconsider their communications channels as well as the communication content. On the other hand, the proactive ones got the opportunity to profit from the situation and to use the pandemic period for marketing innovations, R\&D, new product development, and to get involved in corporate social responsibility as a part of the marketing strategy.

Scholars discuss each sub-topic of this issue providing recommendations on what to do or not to do during the crisis. Lessons from previous economic crises and recessions can be adapted in the pandemic situation, taking into account specific features of COVID-19. Also, there appeared a number of market research with new insights, mostly focusing on changed consumer behaviour. There are several researches on how COVID-19 has impacted marketing (CMO Survey, 2020, 2021; Customer Engagement Report, 2000; The Coronavirus on Advertising Report, 2020; European Marketing Agenda, 2021), which provide a global view. It is obvious that at the end of the first quarter of 2021 the COVID-19 pandemic continues, therefore theoretical and empirical investigations on the COVID-19 impact and its management are still in their beginning phase.

Thus, the problem analysed in the research is that there is no current knowledge of how organisations' marketing management has changed due to the crisis. The object of this research is the change in organizations' marketing management that was caused by the crisis.

Most market studies are global or focusing on the big economy countries. It raises questions whether the same trends are in smaller markets or they behave differently. Thus, the aim of the research is to determine the organizations' marketing management changes conditioned by the COVID-19 pandemic in Lithuania.

The study begins with an overview of the pandemic crisis concept, its overall effect on the state and business organisations. Then the authors, following academic literature, develop a deeper understanding of how the crisis impacts marketing management, explore the insights of the latest market research analysing the COVID-19 impact on marketing, and finally provide original research results, insights, and discussion about the COVID-19 effect on marketing management in Lithuanian business organisations. 
Research methods. To achieve the aim, there have been employed analysis and synthesis of scientific literature, questionnaire research, descriptive statistical analysis, and logistic regression analysis.

\section{SCIENTIFIC SUBSTANTIATION}

\section{Pandemic crisis}

The pandemic covers biological, natural disasters (Finsterwalder and Kuppelwieser, 2020), and by its volume is a large epidemic with such features as a wide geographic extension, disease movement, high attack rates and explosiveness, minimum population immunity, novelty, infectiousness, contagiousness, and severity (Morens et al., 2009; Qiu et al., 2017). COVID-19 is the pandemic, which the world faced in 2020, with the previous three big pandemics in the XX century: Spanish Flu, Asian Flu, Hong Kong Flu (Qiu et al., 2017).

Finsterwalder and Kuppelwieser (2020) state that typically a pandemic goes through different phases (pre-pandemic, pandemic, post-pandemic) with possible new waves in the pandemic phase. The two big waves (spring and autumn/winter) were seen in the COVID-19 case in 2020/2021 and hit all the world on a large scale. In March 2021, the number of confirmed COVID-19 cases worldwide surpassed 120 million, including over 2.6 million deaths. In the middle of March of 2021, $44.2 \%$ of the cases were registered in the US, $34.4 \%$ - in Europe, $11.6 \%$ - in South-East Asia, 5.7\% - in the Eastern Mediterranean, 2.4\% - in Africa, $1.4 \%$ - in the Western Pacific region (World Health Organization, 2021) with a still not declining trendline, followed by the spread of "British", "Brazilian" and "South African" virus mutations and uncertainty about future scenarios for the rest of 2021.

COVID-19, like any other pandemic, led to many consequences all over the world. Typical pandemic consequences, next to health issues, are threatened economics, regional stability, security, political situation, changed social life, disrupted education, mobility, tourism, sporting and leisure (Qiu et al., 2017; Donthu and Gustafsson, 2020). Undoubtedly, the COVID-19 consequences have been no exception. Donthu and Gustafsson (2020) state that market changes became vivid because of the financial pressure. Distortion in demand hit industries: one faced a sharp and unprecedented drop in demand, others - explosive increase in demand, the third ones - muted or lumpy demand (Abdelnour et al., 2020). Industries like hotels, airlines, travelling, cafes and restaurants shrank, others, like Internet-based businesses, have blossomed, a lot of businesses simply closed because of the lockdown. Global supply chains were distorted (Manuel and Herron, 2020) or stopped, intermediaries had to be immediately changed, thus local supply chains stretched (He and Harris, 2020). Countries faced GDP growth losses all over the world (ETUI and ETUC, 2020). Changes in the labour market due to unemployment and underemployment became drastic. In the US, the unemployment after the first COVID-19 wave, in April of 2020, reached an unprecedented level, not seen since data collection started in 1948, in some US regions even beating unemployment rates of the Great Recession (Falk et al., 2021). In the middle of 2020, the number of unemployed in Europe increased drastically as well (ETUI and ETUC, 2020), going lower in EU27 than in 2008. Next to it, the breakthrough of the use of information technology occurred. Face-to-face interaction was replaced by digital interaction ( $\mathrm{He}$ and Harris, 2020). In fact, COVID-19 has accelerated the transition into the age of the Fourth Industrial Revolution (Global Technology Governance Report, 2020). All these changes caused governments and organisations to reconsider the ways how to adjust to the new 
landscape. Therefore, seeking to respond to the crisis effectively, a response from individuals, governments and businesses has to be coordinated (Shrivastava, 1993).

From the business organizations' perspective, a crisis refers to a highly impactful, disruptive and unexpected event emerging from both internal and external environments of a firm, which can threaten its viability, financial status, and strategic goals (Bundy et al., 2016). Such an event is a situation with a drastic and negative impact on an organization, its customers, competitors, employees, and other stakeholders (Crick and Crick, 2020). Following Cankurtaran and Beverland (2020), in order to deal with the crisis, organizations could use a mindset of the innovation process: first disrupting, i.e., changing the things that are currently done, then defining and developing, and finally transforming. Due to the pandemic, organisations had to become agile and transform their organizational design and functions performed, i.e., the pandemic has required to think innovatively. Organisations managed organisational design issues in such ways as on-site work was transformed to remote work, a higher level of real delegation was observed by transferring decision making to local managers, reward systems changed towards more performance-dependent salaries, a higher degree of formalization became necessary to maintain control and even substitution to independent contractors (freelancers) became under discussion (Foss, 2021). The pandemic more or less impacted all functions of organisations, not just organisational design, yet this article focuses mainly on the marketing function and issues related to it.

\section{Impact of pandemic crisis on marketing management}

COVID-19 has changed consumer behaviour, new consumption patterns have emerged (Donthu and Gustafsson, 2020; Hoekstra and Leeflang, 2020; Nielsen, 2020). Such new patterns as focusing on family/community/self, health, digital solutions are considered to be long-lasting changes (Euromonitor International, 2020), followed by other new ones as cooking at home, safety concerns, and shopping online (Kang et al., 2020). Reinvented shopping was one of the salient changes because of the lockdown (Hoekstra and Leeflang, 2020), the usage of the Internet and social media has increased (Donthu and Gustafsson, 2020), as well as customers' appreciation and adoption of digital channels (Deloitte, 2021). All these changes required to launch a series of offerings to satisfy customers' new habits and concerns, to look over marketing strategies, budgets, activities and operations in order to accelerate, enhance or stabilise cash flows.

Marketing strategy. Marketing strategy and activities became vital seeking to improve cash flows during the crisis (Kang et al., 2020). Like the pandemic evolution phases, the business also faces the pre-crisis phase, in which firms aim to detect and prevent a crisis before it occurs, the crisis response phase, when firms handle the crisis and it is the peak, and the post-crisis phase, involving organizational learning (Kim et al., 2019). The marketing strategy should be re-evaluated already in the pre-crisis period, later making only necessary adjustments, though sometimes even that cannot prevent from drastic outcomes. $\mathrm{He}$ and Harris (2020) agree that COVID-19 changed the landscape of organisations compelling them to change their marketing strategies and become agile when reacting to the situation. COVID19 made executives and managers change marketing strategy developing systems, operations and tactics, they had to reach customers in more a water-life strategy rather than a red or blue ocean strategy, and to find entrepreneurial and innovative spirit. Pro-active marketing strategies in a recession result in superior business performance (Srinivasan et al., 2005). Thus, while rethinking marketing strategy, managers have to look from a big picture view, 
reconsidering not only product, price, promotion, place strategies, the use of offline and online channels (Sharma, 2020; Ansari and Ganjoo, 2020) but also re-evaluating the situation as the time of possibilities. According to Srinivasan et al. (2005), companies that see recession as an opportunity for change, achieve superior business results.

Marketing innovations. Searching for new marketing strategies, the importance of marketing innovation arises. Naidoo (2010) argued that marketing innovation can be defined as improvements in product design, placement, promotion, pricing and can be a contributing factor to a firm's survival in an economic crisis. A decade later, Wang et al. (2020) agreed that marketing innovations, especially the ones which can be implemented in a shorter period, compared to technological innovations, which are positioned as a type of incremental innovations (Grewal and Tansuhaj, 2001), appeared suitable for the COVID-19 environment. Thus, organisations should evaluate whether it is a time for marketing innovations and which type of marketing innovations can be appropriate during the pandemic: responsive, collective, proactive, or partnership marketing innovations. Crick and Crick (2020) also stress the importance of collaboration during the crisis giving numerous application examples realised during COVID-19. The authors state that trying to benefit from certain market-level conditions that allow collaboration, as well as to determine the extent of collaboration, taking into account possible negative outcomes, can be the way of marketing innovation implementation.

$R \& D$. There are numerous studies that argue the importance of investing in marketing and R\&D during a crisis. Srinivasan et al. (2005) state that companies respond to recession in two ways: invest in marketing and R\&D or cut marketing expenses heavily. Gulati and Wohlgezogen (2010) agree that the post-recession winners are companies, which spend more on marketing and $\mathrm{R} \& \mathrm{D}$ during the recession, even if they cut costs by focusing on operating efficiency. Hunneman (2020) agrees that research shows a higher increase in return on R\&D investments during a recession. Thus, having resources on $R \& D$, being proactive may lead to competitive advantage in the post-pandemic phase. Nevertheless, the receptiveness of consumers to new products/services is greater during periods of contractions rather than the period of expansion (Hoekstra and Leeflang, 2020).

New products. Along with very costly and time-consuming R\&D innovations, organisations during the crisis can launch market breakthroughs so that to meet new consumer demand (Narayandas et al., 2020). Crisis becomes a good time to reevaluate the range of assortment so that to increase profitability (Hoekstra and Leeflang, 2020), or reevaluate the role of private labels. During the COVID-19 pandemic crisis, some companies have even developed new products (Hoekstra and Leeflang, 2020) not just seeking to survive, but because of the favourable environment for the creation of specifical products that were in great request during this pandemic crisis (Obal and Gao, 2020). The products varied from hand sanitizers, disinfectants, medical, fabric and transparent face masks of various shapes, to apps for mental resilience, digital learning, sporting at home, monitoring social distancing, or even more complex solutions as medical supplies, robot vehicles delivering food or other solutions solving the last-mile problems. Service providers expanded their services, for example delivering drive-in concerts, social distancing dining, precooked dishes, virtual appointments with patients, or offering virtual training assistants.

Pricing. Pricing strategy during the crisis has to be implemented with great care (Hoekstra and Leeflang, 2020). During crises, customer buying behaviour changes. Consumers become more price-sensitive (Van Heerde et al., 2013; Hampson and 
McGoldrick, 2013; Grundey, 2009), especially the mass-market, and less interested in unique products (Hoekstra and Leeflang, 2020). Lowered people's income, lost jobs, uncertainty force them to reduce consumption expenditures and switch to cheaper options (Diallo and Kaswengi, 2016). The business may respond by lowering prices, offering temporary price promotions, and increasing the number of discounts. Some authors even recommend price reductions during the crisis by reallocating marketing budgets from advertising to price discounts (Van Heerde et al., 2013). Otherwise, price promotion works best when the economy grows; when the economy shrinks, consumers are not willing to try new offers (Hunneman, 2020). Looking from a business perspective, there were no ways to lower prices during COVID-19, because an extraordinary situation forced companies to think about how to sustain business and get any revenue. Moreover, the opposite situation evolved in some categories of products, i.e., exploitative pricing increased the demand. It happened due to a shortage of products and raw material, consequently, the prices drove up all over the world (ILOSTAT, 2020) from food products to different healthcare materials such as face masks, disposable gloves, antiseptic, sanitary products, hydro-alcoholic gels, disinfectants, serological tests to COVID-19 antibodies, it also affected funeral and delivery services (OECD, 2020; Abdelnour et al., 2020). Food prices raised particularly, and it had a major impact on the living standards of lower-income households. Abdelnour et al. (2020) provided insights on what companies should or should not do with prices during the pandemic. Pricing recommendations for companies are the following: make sure every pricing action is legal, ethical and community-minded, keep a long-term perspective from the point of customer relationship, strengthen value-focused messaging, create "flex" pricing and even establish a commercial "value council". On the other hand, the following actions should be avoided: taking advantage over customers, assuming that every demand problem can be solved by pricing, relying on old price-sensitivity research, slashing list prices without considering other options, attacking competitors' key accounts without preparation to a sharp response.

Marketing channels. Another field, which was affected by COVID-19 is marketing channels. Marketing channel redesign became a must in most countries (Hoekstra and Leeflang, 2020). COVID-19 caused a sharp increase in demand for online consumption due to decreased visits to offline stores. Not only the issue of comfort, but 'safety first' drove these changes (Moon et al., 2021). The closing of offline stores pushed to open online stores and it boosted e-commerce to a new era. Next to already usual categories in e-commerce, even food retailers have been hit with a level of demand that was difficult to fulfil (Mollenkopf et al., 2021). According to Wang et al. (2020), companies during the COVID-19 crisis had to think about multiple channels to continue selling and delivering offerings. Generally, offline and online marketing channels have a complementary relationship rather than competition (Moon et al., 2021). Due to the pandemic, this statement was even more proved converting offline stores to order pick-up points when physical shopping in the stores was suspended. The delivery service demand and supply have boosted. The need to overlook the supply chain emerged (Hoekstra and Leeflang, 2020). Shortening supply chains, serving homebound customers directly became good solutions during the pandemic (Guillen, 2020). Even B2B sector used strategies such as migrating to digital distribution channels, integrating live streaming for marketing and sales for technical explanations, new products release (Kang et al., 2020). Marketing channel redesign has changed not only channels but entire business models. 
Corporate social responsibility. Rethinking corporate social responsibility could be another direction during the crisis. Manuel and Herron (2020) notice that businesses have seen increased demand for corporate social responsibility activities in response to the pandemic. $\mathrm{He}$ and Harris (2020) state that during the crisis organisations might be discouraged from investing in corporate social responsibility because of the need to focus on core business functions in the short term. However, the pandemic offers a great opportunity to engage in corporate social responsibility initiatives, which could be a starting point in the long run. Along with such motivational factors as short-term results, stakeholders' expectations and/or the good of society (Aguilera et al., 2007) may be corporate socially responsible actions taken during the COVID-19 period. Hoekstra and Leeflang (2020) as well as He and Harris (2020) when analysing the COVID-19 cases refer to companies, which have adapted their goals and launched initiatives on how to contribute to tackling COVID-19 thus demonstrating their corporate social responsibility. Manuel and Herron (2020) review the situation by stating that philanthropic initiatives such as financial and food contributions to support medical workers, food banks and schools, complimentary vacation packages for frontline health workers, reduced costs for COVID-19 treatments, technology classes and laptops for children, phone chargers for hospitals, reduced cost plans from telecommunication providers, even cut salaries of CEOs were seen during the pandemic. Moreover, transformational responses, as adding to or changing an organisation's traditional products and services to accommodate the needs during the pandemic, can be another form of corporate social responsibility, though some of them could be government mandated (Manuel and Herron, 2020).

Marketing \& advertising budget. Despite the importance of marketing activities during the pandemic, one of the most common reactions of organisations is cutting marketing costs to the minimum, mainly seeking to protect short term profits (Deleersnyder et al., 2009); however, it is the primary measure taken by some companies confronting short term cash flow issues (Kang et al., 2020). Researchers assume that adding a new product line, switching to digital distribution channels, advertising and promotion help to accelerate cash flows and mitigate the crisis impact, but all this needs the marketing budget. However, Deleersnyder et al. (2009) and Lamey et al. (2012) argue the need to maintain or increase the marketing spending during recessions.

Similar arguments fit when discussing the advertising budget. Hunneman (2020) summarises that there is no single answer to whether it is good to cut the advertising budget during the crisis, yet the literature is not conclusive too. The general pattern during the crisis is to decrease spending, mainly communication/advertising budgets (Hunneman, 2020; Hoekstra and Leeflang, 2020). On the other hand, companies that maintain advertising and communication at the same level have the opportunity to increase their SOV (share of voice), if competitors become more silent, which has been evident during the COVID-19 crisis period (Hoekstra and Leeflang, 2020). Lamey et al. (2012), Dekimpe and Deleersnyder (2018) imply that maintaining and increasing the advertising budget often results in better market share and overall performance. However, for some industries, such as pharmaceuticals, health \& healthcare, online retail, alcoholic beverages, gaming, telecommunications FMCG, the crisis was a good time to increase their advertising budgets because of the changing consumption patterns and increased demand (The Coronavirus on Advertising Report, 2020).

Communication. Due to COVID-19, communication in the short term was more focused on the existing customers rather than on acquiring new ones (Hoekstra and Leeflang, 2020). In the time of crisis, the dominance of communication channels has changed: many tend to 
put money where they are most easily measured focusing on ad spending in media that could drive direct sales outcomes (The Coronavirus on Advertising Report, 2020). Though consumers' time spent watching TV has increased, but even more has increased their use of streaming services (The Coronavirus on Advertising Report, 2020). Following previous arguments, digital channels became a suitable medium, i.e., digital marketing, social media, SEO, email exploitation became pillars during COVID-19 (Sharma, 2020; Ansari and Ganjoo, 2020). Analysing the content, Edelman Trust Barometer (2020) indicates that customers expected ads to recognise that it is not business "as usual", they expected empathy from brands, hearing about business efforts to help people in the crisis. Solutions, but not selling became crucial. Humorous ads were not suitable for this period (Edelman Trust Barometer, 2020). He and Harris (2020) agree that communicating with empathy and solving problems were the key components for maintaining brand loyalty during the crisis.

Summarising it can be stated that the COVID-19 pandemic had a visible impact on marketing in searching for new strategies how to adjust to new consumer behaviour patterns or the changed demand and supply. During the pandemic period, different challenges have emerged and organisations are still coping with the following issues: marketing strategy adjustment, the search for marketing innovations, $R \& D$, new product development, pricing, marketing channel redesign, reconsideration of corporate social responsibility as a part of the marketing strategy, re-evaluation of marketing, advertising and communication budgets.

\section{Market research results: the impact of COVID-19 on marketing management} worldwide

The impact of COVID-19 on marketing management became an object of market research, conducted by numerous worldwide known market studies and consulting companies. Significant market research results of the impact of COVID-19 on marketing are provided in CMO Survey (2020, 2021), Customer Engagement Report (2000), The Coronavirus on Advertising Report (2020), European Marketing Agenda (2021). The COVID-19 impact on Lithuanian marketing organisations was investigated by European Marketing Agenda (2021), Lithuanian Marketing Association, and KOG Institute (Balčiūnienè, 2020).

CMO Survey $(2020,2021)$ was conducted in the US in June of 2020 after the first COVID-19 wave ( $\mathrm{N}=274,97 \%$ of respondents VP-level or above) and in January of 2021 still being in the second COVID-19 wave ( $\mathrm{N}=356,94.5 \%$ of respondents VP-level or above). CMO Survey (2020) shows that during the first wave of the pandemic in the US increased openness among customers to new digital offerings introduced during the pandemic $(84.8 \%)$, value placed on digital experiences $(83.8 \%)$. Marketing budget as a percent of firms budget and revenues rose as never before reflecting attempts to retain customers during the first wave (CMO Survey, 2020) and declined in January of 2021, but still was higher than in January of 2020, i.e., the pre-pandemic level (CMO Survey, 2021). In the US, during the first wave, $30.3 \%$ of marketers had experienced no changes in the marketing budget (CMO Survey, 2020). Changes in marketing spending on customer experience increased during the first wave but have decreased through the second one. Digital marketing became a pillar for companies during the pandemic year. Social media spending increased dramatically during the first wave but has decreased during the second one, nevertheless, its contribution to companies' performance is undeniable. CMO Survey $(2020,2021)$ states that $9 \%$ of marketing jobs were lost during the first wave, resulting in an $8.2 \%$ loss during the pandemic year. Expected marketing hiring dropped to historic lows during the first wave, but in January of 2021 
rebounded beyond the pre-pandemic levels. During the first wave, marketing employees' functions were mostly focused on promoting a company and its offerings online (68.6\%), developing new advertising and promotional strategies $(65.7 \%)$, reaching out the current customers with information (65.2\%), and improving digital interfaces for customers $(61.8 \%)$. The first wave did not change the outsourcing of the marketing landscape. Respondents stated that they focused more inside the funnel (58.7\%) versus the non-funnel $(41.3 \%)$. Thus building brand value $(33 \%)$ and retaining customers $(32.6 \%)$ were the main goals.

COVID-19 led to the outcome that the marketing function in the US has increased in importance $-62.3 \%$ after the first wave of COVID-19 (CMO Survey, 2020) and $72.2 \%$ after the pandemic year (CMO Survey, 2021).

Customer Engagement Report (2000) (N=400 US and UK brand marketers) presents research conducted in June of 2020 summarising the impact of the first wave of COVID-19. The results reveal that $52 \%$ of respondents increased their marketing spending. The top industries, which increased spending was health, insurance, and retail. Furthermore, 50\% of respondents planned to move more projects and staff in-house, $22 \%$ - to outsource more often, while $28 \%$ indicated that no changes were planned.

The Coronavirus on Advertising Report (2020) ( $\mathrm{N}=200$ US marketing and agency professionals), conducted during the first wave of COVID-19, states that most companies were in a self-preservation mode, i.e., $89 \%$ of respondents indicated their advertising budgets were impacted by the pandemic. Based on the Report, advertisers were modifying their budgets in the short term, not slashing them: $49 \%$ stopped or pulled a campaign mid-flight, $48 \%$ held back a campaign from launching until later in the year, $45 \%$ adjusted the media type usage or shifted budgeting among media types, $38 \%$ paused all new advertising efforts until later in the year, and $34 \%$ cancelled a campaign completely (pre-launch). Among $61 \%$ of advertisers who maintained or reallocated their budgets, $25 \%$ maintained or shifted their budget to paid research, i.e., $19 \%$ - to social, $16 \%$ - to digital video, $13 \%$ - to display. Actually, Google and Facebook became the biggest beneficiaries of budget allocations.

According to European Marketing Agenda (2021) (N=635 marketing and sales executives), the main effects of the COVID-19 pandemic on marketing operations in Europe can be named as the following: increased focus on digitalisation $(50.4 \%)$, the main focus of attention on marketing operations (execution) $(44.9 \%)$, greater need for KPIs and measurable values $(38 \%)$, budget reduction $(32.4 \%)$, increase in cross-functional teamwork and project work $(30.7 \%)$, reallocation of spending $(26.6 \%)$, reorganisation of marketing processes $(22.2 \%)$, restructuring of existing business models $(20.8 \%)$, focus on performance marketing (20.3\%), development of new sales channels (19.5\%), employee training and development $(15.6 \%)$, focus on supply chains and efficient supplier networks (10.9\%), reduction in organisational obstacles $(9 \%)$. Also, it is noticed that companies in different countries have attempted to cope with the COVID-19 crisis in different ways: from budgetary reductions to restructuring the existing business models or increasing attention to further digitalisation. Based on the same European Marketing Agenda (2021) research, COVID-19 changed the priorities of marketing activities. Though digitalisation remained the Top 1 priority, brand strategy and management (Top 2 priority in 2020 before the COVID-19 pandemic), and content marketing and optimisation (Top 3 priority in 2020 before the COVID-19 pandemic) were replaced by CRM database and management (Top 2 priority in 2021, i.e. during/after the COVID-19 pandemic) and marketing spend optimisation (ROMI) that was the Top 3 priority in 2021 during/after the COVID-19 pandemic. 
Whereas analysing how COVID-19 impacted marketing management in Lithuania, European Marketing Agenda (2021) states that the primary effect was the budget reduction in general, secondary - reallocation of spending, and tertiary - reorganisation of marketing processes. The Lithuanian priorities remained consistent with those observed in the previous year. The dominant topics for Lithuania were: digital marketing $(43 \%)$, brand strategy and management (32.2\%), innovation and product development $(20.7 \%)$, following the priorities of social media marketing $(20.7 \%)$, and marketing planning best practices (19.8\%). Less focus was placed on big data and digital transformation compared to other countries. Based on the research, conducted by Lithuanian Marketing Association and KOG Institute (Balčiūnienè, 2020), $22 \%$ of the surveyed companies in Lithuania $(\mathrm{N}=270)$, have radically changed their marketing strategy, yet the majority $(59 \%)$ made minor changes to it. The main changes happened in business restructuring (33\%) and online commerce $(24 \%)$. Almost half of the surveyed companies $(44 \%)$ have reduced their advertising budgets, and $28 \%$ said that their budgets had not changed or had been redistributed to other advertising channels, yet $11 \%$ indicated that they increased their budget during the crisis. The marketing budget has been reduced to external agencies and consultants: $44 \%$ of organisations reduced or stopped cooperation, i.e., $37 \%$ reduced, $7 \%$ completely stopped, and only $9 \%$ said they had increased their cooperation. According to the research results, one-fifth of companies indicated that the functions of marketing staff had been expanded or redistributed, the workload had increased, and employees had been given new tasks. However, $14 \%$ stated that the marketing team had shrunk or stopped existing at all due to savings or workload reductions. On the other hand, the importance of the marketing manager's role has strengthened. Given the Lithuanian Marketing Association and KOG Institute research, the marketing manager in a crisis period significantly contributes to the strategic decision-making and implementation of the organisation: almost a third of them develops and plans strategic actions (28\%), a quarter (24\%) actively participates in decision-making, and nearly a fifth (17\%) contributes with their ideas and recommendations to the overall organisation's performance (Balčiūniené, 2020).

\section{RESEARCH METHODOLOGY}

Seeking to determine the organisations' marketing management changes induced by the COVID-19 pandemic crisis, exploratory research was applied. The questionnaire research method was chosen to conduct the research. A questionnaire was comprised by the authors based on the marketing management aspects that might have been influenced by the crisis as implies the theoretical analysis. Additionally, given that organisations' overall performance is related to marketing management, the questionnaire consisted of the three main parts:

- Questions regarding the changes that appeared in organisations' overall performance induced by the COVID-19 crisis.

- Questions regarding the changes in organisations' marketing activities induced by the COVID-19 crisis.

- Demographic questions.

The same questions were provided for the three time periods:

1) the time period of the first COVID-19 wave compared to the time before the pandemic;

2) the time period between the two waves of COVID-19 compared to the period of the first COVID-19 wave; 
3) the time period of the second COVID-19 wave compared to the period of the first COVID-19 wave.

The questionnaire covers multiple choice questions, Likert scale, and open questions. First of all, the questionnaire was delivered to three marketing experts and was revised according to their remarks to ensure content validity. Then, a pilot study was conducted. After the pilot study, final corrections were made, and the questionnaire was verified. The full questionnaire is available from the authors upon request.

The questionnaire research was conducted in Lithuania, from February 1 to February 14, 2021. Due to the national quarantine and because of the COVID-19 pandemic, the questionnaire was provided online. The respondents filled out the survey in an online survey platform poll-maker (www.poll-maker.com). Simple random sampling was applied. Following the aim of the research, the scope consists only of Lithuanian organisations that are pursuing some level of marketing activity. Thus, Lithuanian Marketing Association, which holds a database with a list of specified organisations, sent out the link to the questionnaire to the randomly selected organisations that pursue some level of marketing activity.

In the study, that was performed in Lithuania participated 127 respondents who fully completed the questionnaire (a margin of error is $9 \%$ ), giving a response rate of $33 \%$. The respondents' demographic profile is presented in Table no. 1.

Table no. 1 - Demographic characteristics of respondents

\begin{tabular}{|c|c|c|c|c|c|c|c|c|c|}
\hline & : & & 莺 & & 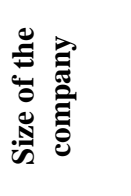 & & 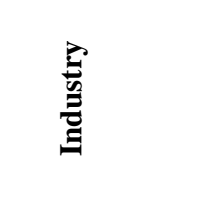 & & 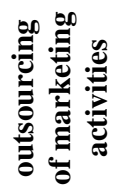 \\
\hline 离 & 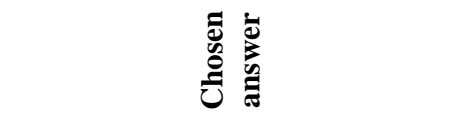 & ت & 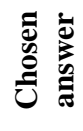 & : & 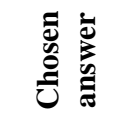 & 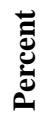 & 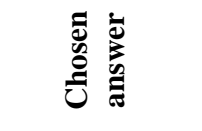 & : & 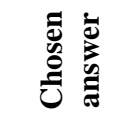 \\
\hline 18 & CEO & 31 & $\mathrm{~B} 2 \mathrm{C}$ & 31 & $\begin{array}{l}\text { Very } \\
\text { small }\end{array}$ & 15 & Marketing & 33 & $\begin{array}{c}\text { Do not } \\
\text { outsource }\end{array}$ \\
\hline 35 & CMO & 42 & B2B & 25 & Small & 9 & Manufacturing & 31 & $\begin{array}{l}\text { Outsource } \\
\text { up to } 25 \%\end{array}$ \\
\hline 8 & $\begin{array}{l}\text { Managers of departments related to } \\
\text { marketing }\end{array}$ & 22 & $\begin{array}{l}\text { B2C } \\
\text { and } \\
\text { B2B } \\
\end{array}$ & 27 & Medium & 6 & Engineering & 19 & $\begin{array}{c}\text { Outsource } \\
\text { from } 26 \% \\
\text { to } 50 \%\end{array}$ \\
\hline 22 & Specialists of marketing & 5 & $\begin{array}{c}\mathrm{B} 2 \mathrm{C}, \\
\mathrm{B} 2 \mathrm{~B}, \\
\text { and } \\
\mathrm{B} 2 \mathrm{G}\end{array}$ & 26 & Large & 6 & Culture & 11 & $\begin{array}{c}\text { Outsource } \\
\text { from } 51 \% \\
\text { to } 75 \%\end{array}$ \\
\hline 6 & $\begin{array}{l}\text { Not marketing specialists, but } \\
\text { performing certain marketing } \\
\text { activities in the company }\end{array}$ & - & - & 1 & Other & 6 & Education & 6 & $\begin{array}{l}\text { Outsource } \\
\text { from } 76 \% \\
\text { to } 100 \%\end{array}$ \\
\hline 2 & Marketing freelancers & - & - & 1 & $\begin{array}{c}\text { Did not } \\
\text { specified }\end{array}$ & 58 & Other & - & - \\
\hline 2 & Other & - & - & - & - & - & - & - & - \\
\hline
\end{tabular}


As it can be seen, most of the respondents are CMO's (35\%), CEO's (18\%), and specialists in marketing (22\%). Most of the respondents are from the B2B sector (42\%). Actually, $31 \%$ of the respondents are from the B2C sector and $22 \%-$ are working in both B2C and B2B sectors. Respondents work in companies of various sizes: $31 \%$ of companies are very small, 25\% - small, 27\% - medium, and 26\% - large companies. Industries which the respondents represent also vary, i.e., $15 \%$ of companies operate in the marketing industry, $9 \%$ - in manufacturing, $6 \%$ - in each of these industries: engineering, culture, and education. The rest $58 \%$ of companies cover different industries each represented by few percent of respondents: accounting/finance/audit; insurance; IT; accommodation and meals; medicine, health care, beauty services; pharmacy, life sciences; real estate; human resources; trade/services; warehousing/logistics/transport; construction; law; tourism, entertainment; media, and publishing. Finally, most of the respondents' companies are not outsourcing or outsourcing up to $25 \%$ of marketing activities (respectively $33 \%$ and $31 \%$ ).

For the analysis of research results, the authors applied descriptive statistics and logistic regression analysis. Microsoft Excel and IBM SPSS Statistics software products were used for the statistical analysis of the questionnaire research results.

\section{RESEARCH RESULTS}

Changes in organisations' overall performance induced by the COVID-19 crisis

Analysing the distribution of evaluations of the impact of COVID-19 on organizations' performance indicators, namely demand, income, expenditure, and a number of employees (see Figure no. 1), it is obvious that during the first COVID-19 wave all the above-named indicators decreased a little or significantly. A little or significant decrease in demand experienced $51 \%$ of organisations, a little or significant decrease in income experienced $57 \%$ of organisations, a decrease in expenditure $-49 \%$ of organisations, and in a number of employees $-33 \%$ of organisations.

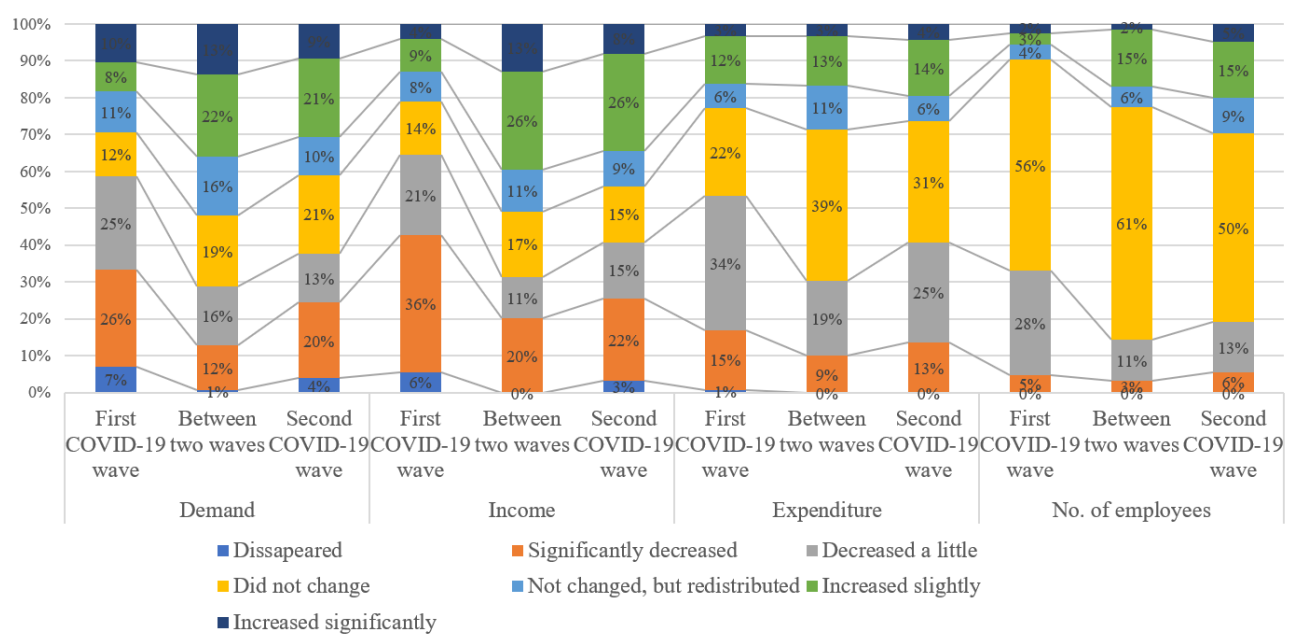

Figure no. 1 - Distribution of evaluations of the impact of COVID-19 waves on the organizations' performance indicators 
Yet the number of employees is the only indicator that did not change in most of organisations (56\%) during the first COVID-19 wave. Between the two COVID-19 waves most of the organisations slightly increased their demand and income (respectively up to $22 \%$ and $26 \%$ ), whereas expenditure and the number of employees did not change (respectively in $39 \%$ and $61 \%$ of organisations). It is worth mentioning that $20 \%$ of organisations witnessed a significant income decrease between the two COVID-19 waves. Hence, for nearly a quarter of organisations income increased slightly, and for one-fifth of organisations the income decreased significantly after the first wave. During the second COVID-19 wave, demand significantly decreased (20\%), did not change (21\%), and increased slightly (21\%) for nearly the same number of organisations - one-fifth of companies. Thus, a smaller percentage of organisations experienced a demand decrease (slight or significant) during the second COVID-19 wave if compared to the first COVID-19 wave. During the second COVID-19 wave, $22 \%$ of organisations recorded a significant income decrease (a little or significant decrease recorded $37 \%$ of organisations), while $26 \%$ of organisations increased slightly their income. Hence, again, income decreased for a smaller percentage of organisations (slightly or significantly) during the second COVID-19 wave if compared to the first COVID-19 wave. Expenditure did not change during the second COVID-19 wave in $31 \%$ of organisations, whereas $38 \%$ of organisations recorded a little or significant decrease in expenditure. Finally, during the second COVID-19 wave the number of employees did not change in half of the organisations, increased slightly or significantly in $20 \%$ of organisations, decreased slightly or significantly in $19 \%$ of the surveyed organisations.

The results of sales channels of organisations (Figure no. 2) show that before the first wave of the crisis $61 \%$ of organisations used both channels - online and physical stores. During the first wave of COVID-19, this percentage dropped to 39\% while the percentage of firms using only online channels increased from $13 \%$ to $49 \%$. Between the first and second COVID-19 waves the percentage of organisations that used both channels - online and physical stores - increased up to $68 \%$. On the contrary, the percentage of organisations using only online channels dropped to $20 \%$, i.e., decreased compared to the period during the first wave of COVID-19 but increased compared to the period before the pandemic. In fact, the percentage of organisations using both channels (online and physical stores) remained the same during both waves of the pandemic (39\%), whereas $50 \%$ of organisations used only online channels. However, the percentage of organisations using only physical channels has been constantly dropping at each analysed period $-26 \%$ before the crisis, $13 \%$ during the first wave, $12 \%$ percent between the two waves, and $11 \%$ during the second wave of COVID-19.

Distribution of evaluations of the impact of the COVID-19 wave on channels of organisation is presented below in Figure no. 3. The survey results prove that during the first wave of COVID-19, between the two waves, and during the second wave of COVID-19 most of the organisations did not change the place of their business but made online business more active compared to the period before the pandemic. 


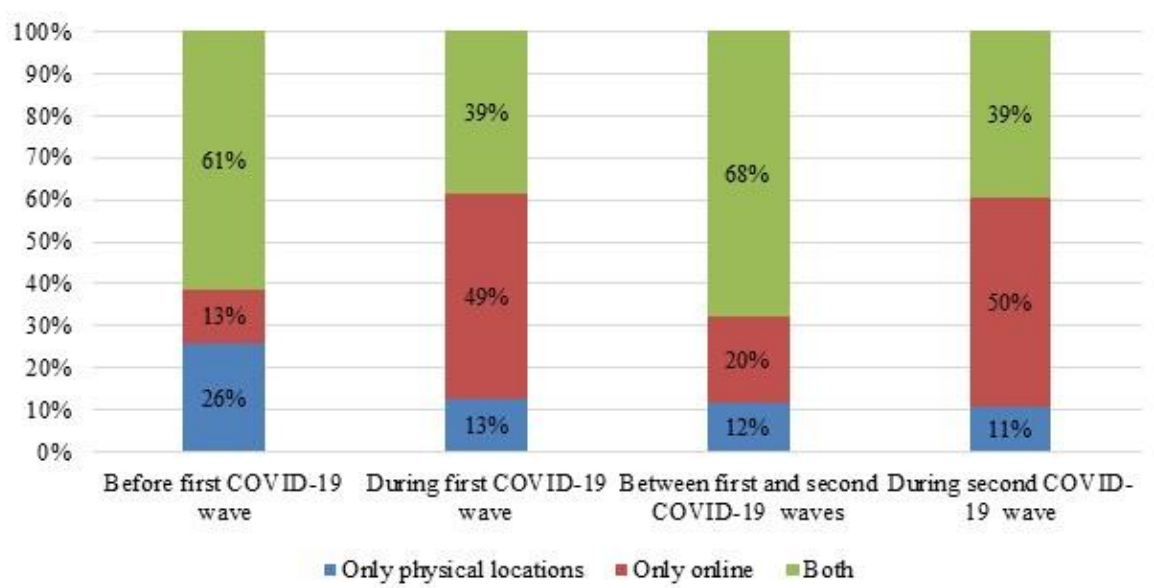

Figure no. 2 - Sales channels of organisations

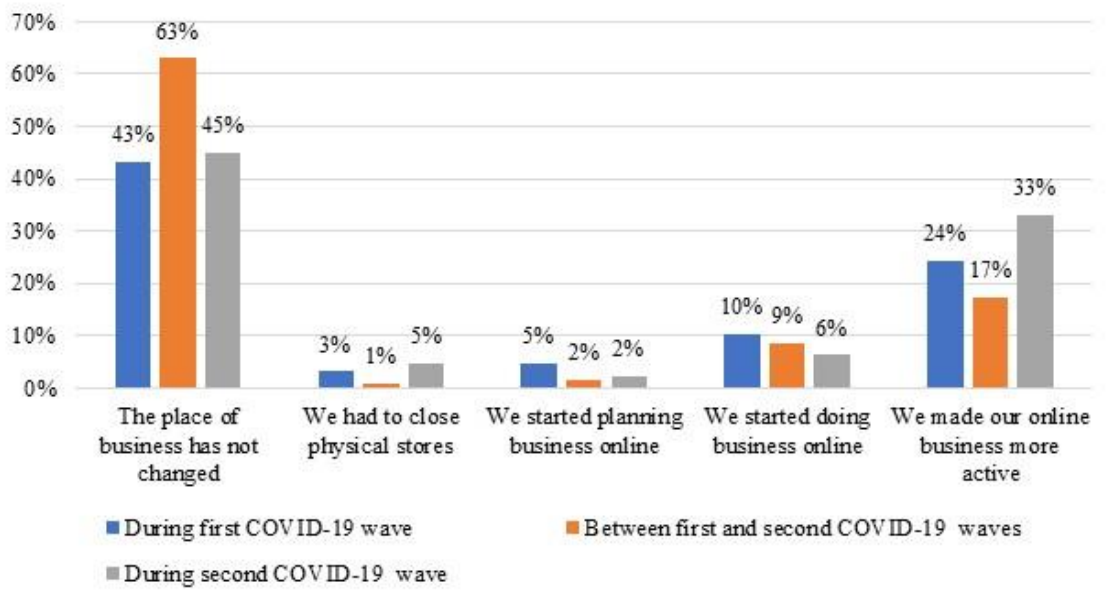

Figure no. 3 - Distribution of evaluations of the impact of COVID-19 waves on channels of organisation

When asked to specify what other impact the COVID-19 waves had on their organisations' performance, the respondents pointed out an increase in mobile customers, a decrease in the growth of the company as well as a decrease in the number of customers with impulsive buying behaviour. Moreover, there was a growing need for specialised employees to work with online channels and social media. Respondents also revealed psychological consequences and an increased number of online rivals.

\section{Changes in organisations' marketing activities induced by the COVID-19 crisis}

More than three-quarters of respondents indicated that the role of the marketing manager in the context of strategic organisational decision-making and implementation did not change or became even more important during the pandemic period. 
When asked to evaluate the impact of COVID-19 on the marketing strategy, $20 \%$ of respondents revealed that it had a substantial impact on the marketing strategy, $72 \%$ responded that it had a little impact on the marketing strategy, 27\% declared that it had no impact on the marketing strategy, and $2 \%$ of respondents did not know the impact of it or it was confidential. The respondents who indicated a substantial or little impact on the marketing strategy during the first COVID-19 wave, specified such issues as a decreased advertising budget, decreased activities, reorganised communication channels, and the focus on ecommerce. However, the respondents who indicated a substantial or little impact on the marketing strategy during the second COVID-19 wave, pointed out such issues as an increased advertising budget (contrarily to the first wave), no changes (as they had been already adapted after the first wave), even greater focus on e-commerce, positioning organization's stability, or again a decreased advertising budget.

The distribution of evaluations referring to the marketing strategy changes due to the pandemic crisis is presented below in Figure no. 4. Nearly half of the organisations changed their marketing actions a little during all analysed periods - the first wave, between the two waves, and during the second wave. Findings reveal that $37 \%$ of organisations did not change their marketing actions between the two waves of COVID-19, 28\% did not change their marketing actions during the second COVID-19 wave, and 16\% did not change the actions during the first wave. The rest of the organisations that are not included in the percentages provided in Figure no. 4 did not know whether their marketing strategy was changed.

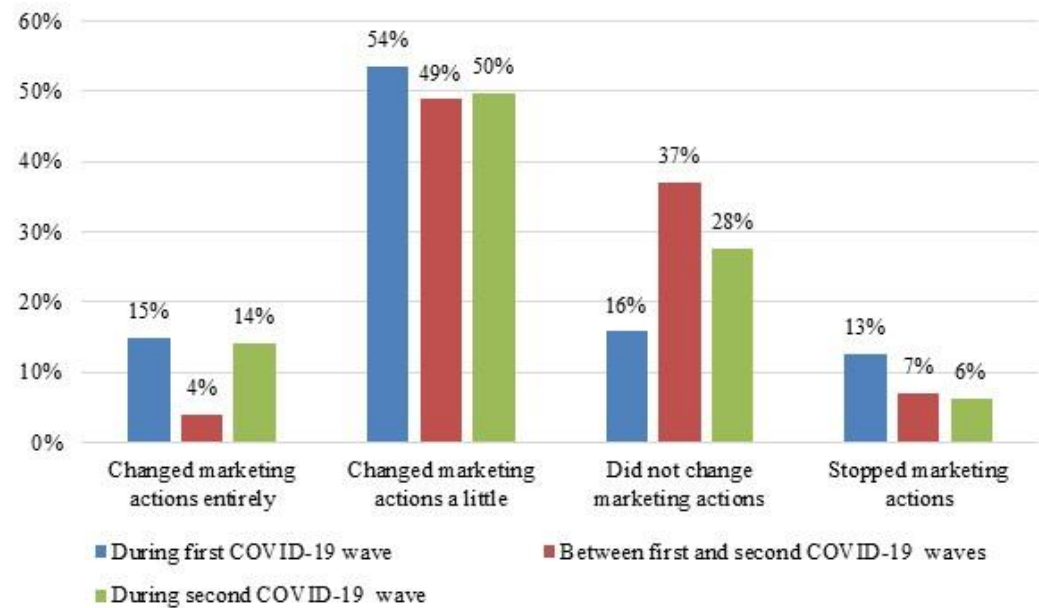

Figure no. 4 - Distribution of evaluations of the marketing strategy change due to the COVID-19 crisis

Marketing actions that have been taken by organisations due to the COVID-19 pandemics are presented in Figure no. 5. 


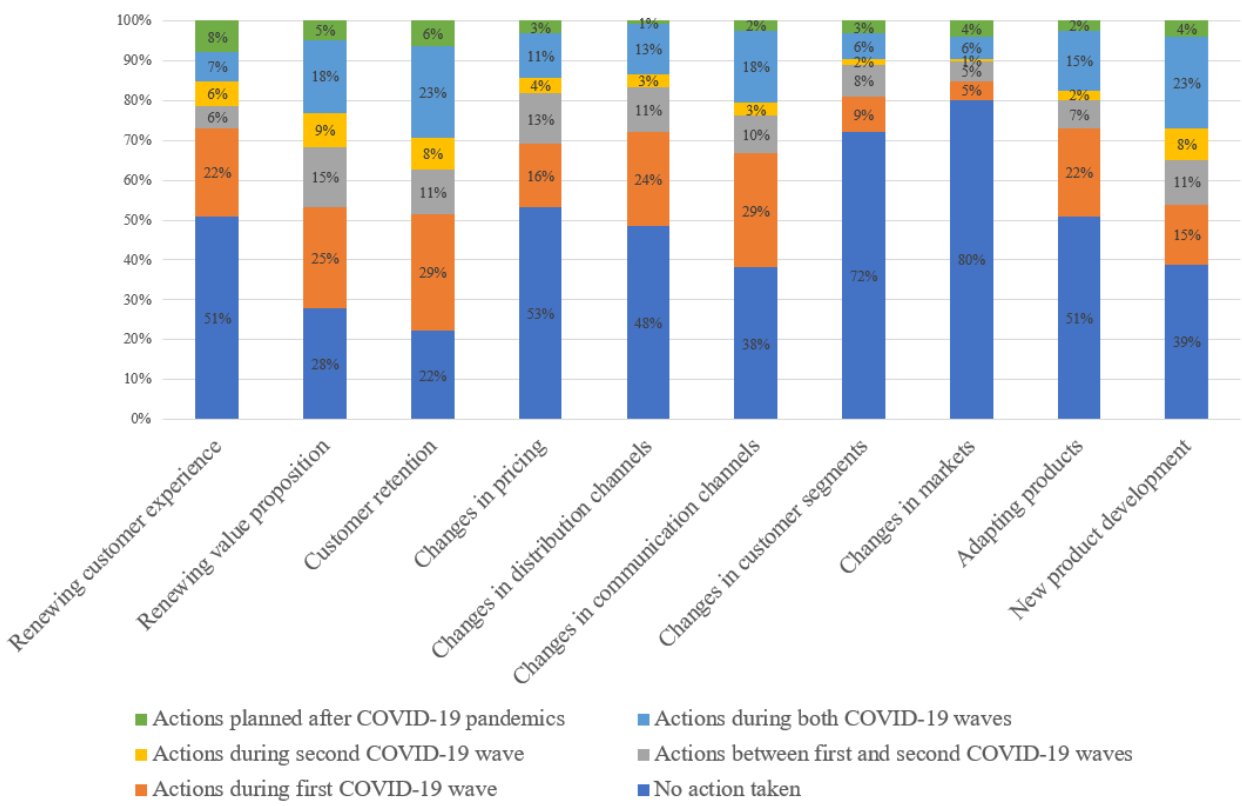

Figure no. 5 - Marketing actions taken due to the COVID-19 pandemic

In this respect, such actions as focusing on renewed customer experience or making changes in pricing and distribution channels, were not taken by most organisations or were taken during the first COVID-19 wave. Actions related to renewing value proposition, customer retention, changes in communication channels, product adaptation and new product development, were not taken by most of organisations during the first wave or both waves. In fact, most of organisations did not make changes in customer segments or markets during all analysed periods.

The opinion of respondents on whether the global recommendation to decrease the marketing budget during the crisis was followed in their organisation, has distributed the following: $43 \%$ of respondents confirmed positively, $38 \%$ of respondents replied negatively, $9 \%$ of respondents did not know, and $9 \%$ of respondents answered they do not have the marketing budget.

Overall, 113 respondents revealed how the COVID-19 crisis has affected their companies' marketing budget. As it can be seen in Figure no. 6, during the first COVID-19 wave, $27 \%$ of organisations did not change it, $38 \%$ of organisations decreased it (significantly or slightly), and $12 \%$ - suspended it. 


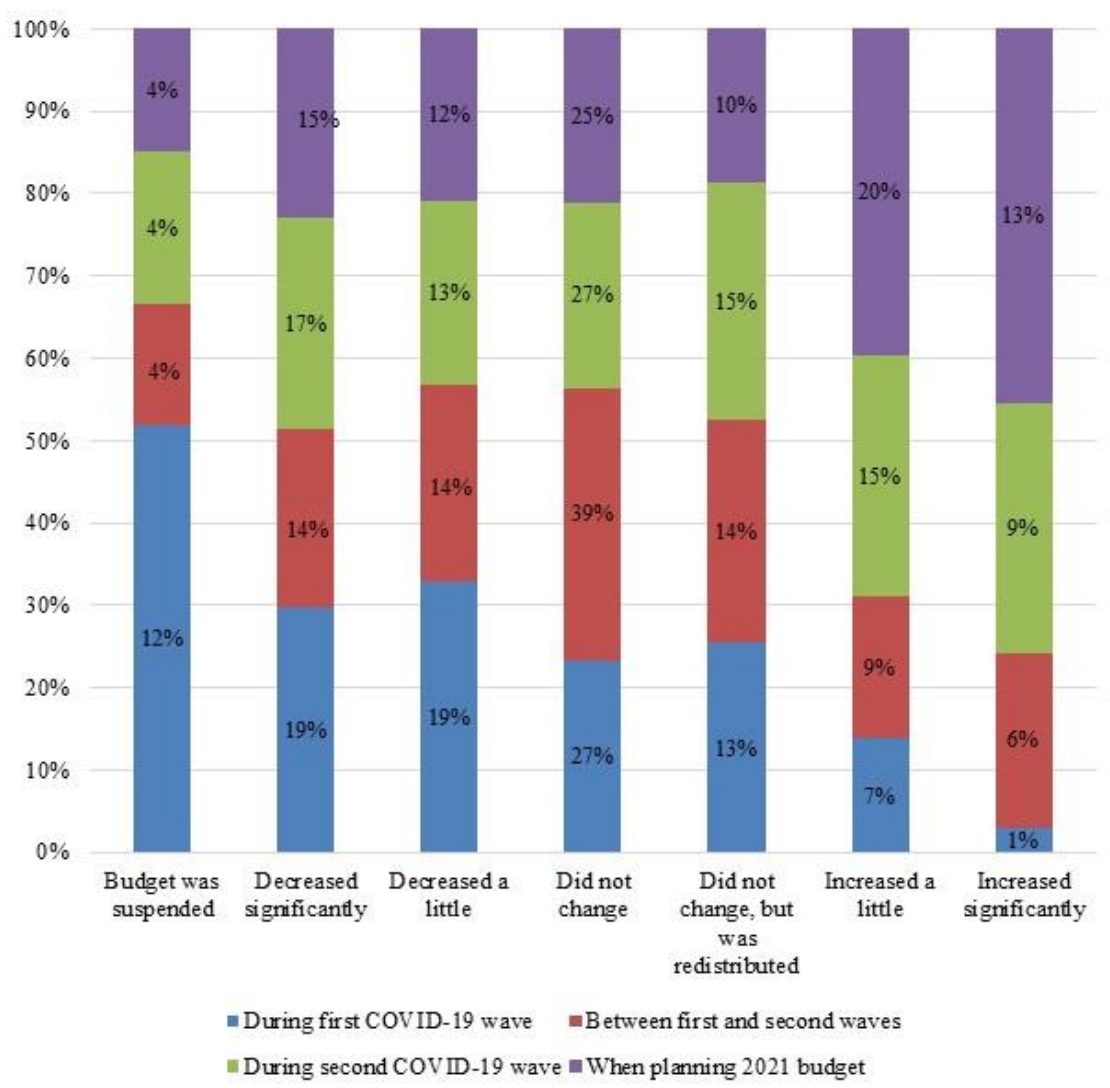

Figure no. 6 - Distribution of evaluations of the marketing budget change because of the COVID-19 crisis

Between the first and second waves of COVID-19, most of the organisations (39\%) did not change their marketing budget. During the second COVID-19 wave $27 \%$ of organisations did not change it, $30 \%$ - decreased it (significantly or slightly), and $4 \%$ - suspended it. The marketing budget was redistributed in $15 \%$ of organisations, whereas $24 \%$ of organisations increased it (significantly or slightly). The same can be observed when we analyse the planning of the 2021 budget, i.e., 25\% of companies did not change the budget, $27 \%$ of organisations decreased it (significantly or slightly), and 33\% of organisations increased it (significantly or slightly).

In general, $78 \%$ of respondents revealed that they have an advertising budget. The evaluations of their advertising budgets' changes caused by the COVID-19 crisis are presented in Figure no. 7. 


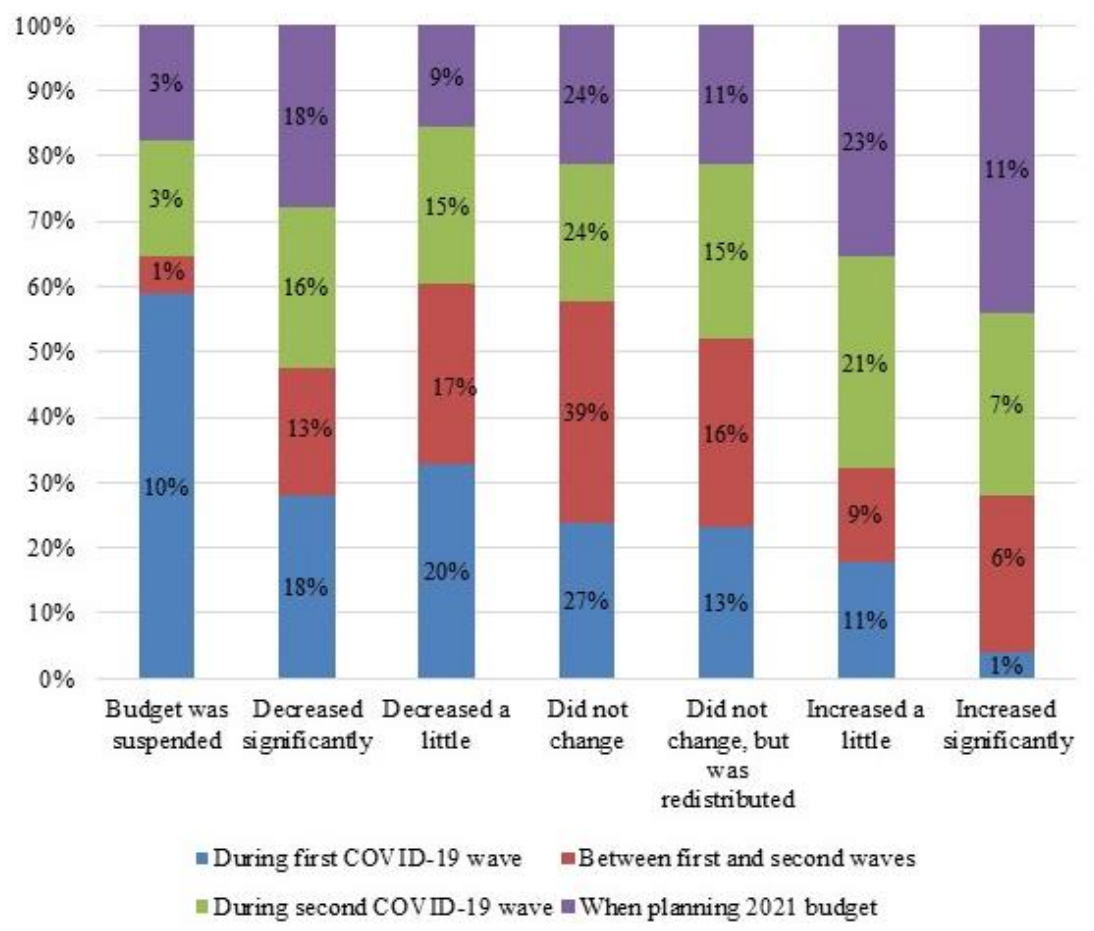

Figure no. 7 - Distribution of evaluations of the advertising budget's changes caused by the COVID-19 crisis

Hence, the results have distributed as follows: during the first COVID-19 wave, 27\% of organisations did not change this budget, 38\% - decreased it (significantly or slightly), and $10 \%$ - suspended it. Between the first and second waves of COVID-19, most of the organisations (39\%) did not change their advertising budget. During the second COVID-19 wave, we observe a similar tendency, i. e. $24 \%$ of organisations did not change it, $31 \%$ decreased it (significantly or slightly), and 3\% - suspended it, whereas $15 \%$ of companies redistributed it, and $28 \%$ - increased it (significantly or slightly). Moreover, when planning the 2021 budget, $24 \%$ of organisations did not change anything, 27\% - decreased the budget (significantly or slightly), and $34 \%$ - decided to increase it (significantly or slightly).

According to the results, $81 \%$ of respondents revealed that they have a marketing team or a department at their organisation. Evaluations of changes in their marketing department induced by the COVID-19 crisis are presented in Figure no. 8. It is observed that $72 \%$ of organisations did not change the marketing department either during the first or the second waves, alike happened in between the COVID-19 waves $-73 \%$ of organisations did not change their marketing department.

The main reasons that induced changes in the marketing department were pointed out as the company's growth, a decrease of marketing budget or workload. Analysing how the crisis has affected the marketing team's functions, it was revealed that communication became more intense, fewer marketing functions were outsourced, workers got more responsibility, there was a need for e-commerce growth, or it did not change at all. 


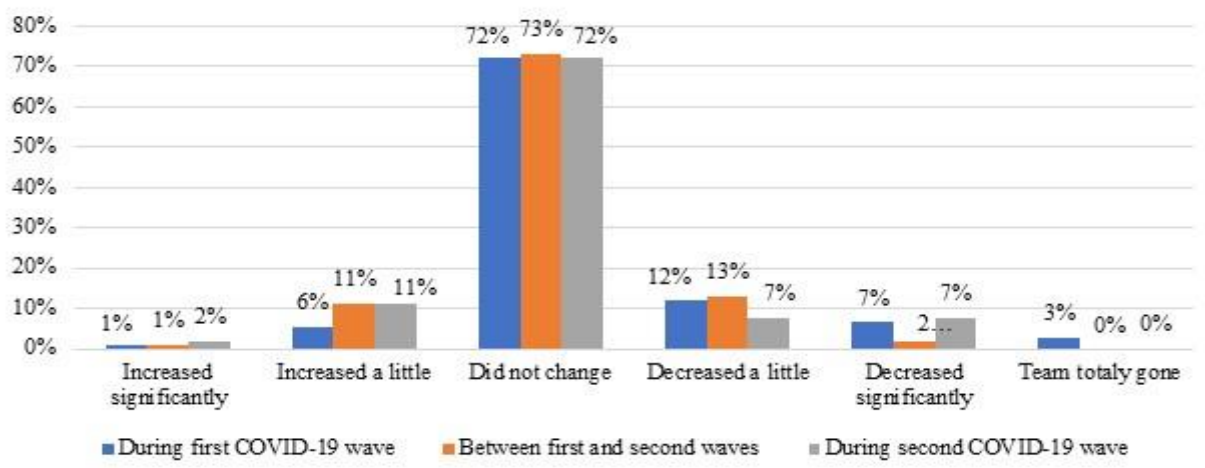

Figure no. 8 - Distribution of evaluations of the marketing department's changes caused by the COVID-19 crisis

It's worth mentioning that $48 \%$ of respondents indicated that before the crisis they collaborated with external agencies/consultants (see Figure no. 9). However, some respondents did not answer this question but expressed their opinion about collaboration with external agencies/consultants and its changes that were caused by the crisis. Overall, $62 \%$ of respondents provided an evaluation of the collaboration with external agencies/consultants and related changes that occurred because of the COVID-19 crisis. Hence, 34\% of organisations did not change their collaboration with external agencies/consultants during the first wave and in between the two waves, whereas $28 \%$ of organisations behaved alike during the second COVID-19 wave. Besides, during the first COVID-19 wave, $22 \%$ of organisations decreased a little the number of orders related to external agencies/consultants' collaboration. Respectfully, during the second wave, $19 \%$ of companies redistributed their tasks related to external agencies/consultants, and $18 \%$ of companies slightly increased the number of orders.

Explaining the reasons for such changes in the above-mentioned collaboration, the respondents indicated that moving services to the Internet has reduced their cost, and so have marketing budgets.

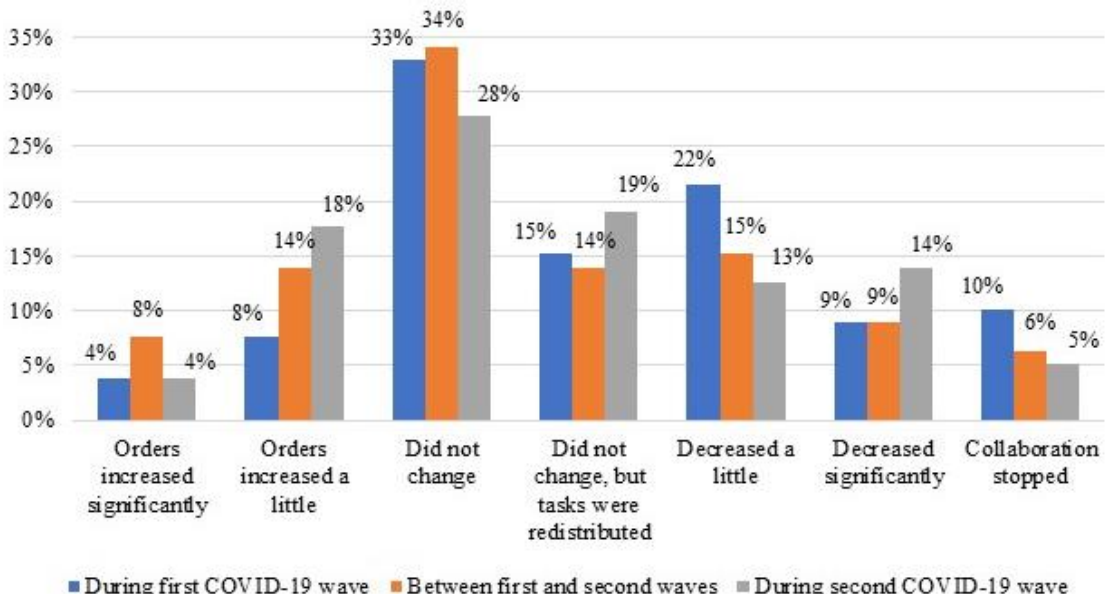

Figure no. 9 - Changes in collaboration with external agencies/consultants due to the COVID-19 crisis. Distribution of respondents' evaluations 
In the questionnaire, 123 respondents indicated whether they are already considering some post-crisis actions (see Figure no. 10).

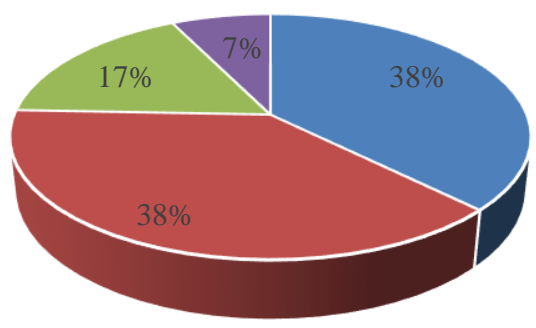

\author{
- No, because now we \\ are concentrating on \\ current issues \\ - Yes, we have already \\ made tactical decisions \\ - Yes, we have already \\ made strategic \\ decisions
}

Figure no. 10 - Distribution of evaluations of the considered post-crisis actions

As it can be seen, there are two equal parts of organisations, each with a percentage of $38 \%$ - one part is not considering post-crisis actions as they are still concentrated on current issues, whereas another part of organisations is planning post-crisis actions and have already made tactical decisions. Overall, $17 \%$ of organisations are planning post-crisis actions and have already made strategic decisions.

In general, the evaluation of the total effect of the COVID-19 crisis on organisation's performance has distributed as follows: $29 \%$ of respondents indicated a positive effect, $61 \%$ indicated a negative effect, and $10 \%$ of respondents did not notice any effect on organisation's performance.

The influence of the marketing and advertising budgets' changes on the organisation during the first wave of the pandemic crisis

In order to determine the influence of the marketing and advertising budget's change on organisations during the first wave of the pandemic crisis, logistic regression was applied (see Table no. 2). Regarding the influence of the marketing budget's change during the pandemic crisis (first wave) on the effect of the pandemic crisis on the organisation, the logistic regression model is statistically significant, $\chi^{2}(1)=15.698, \mathrm{p}<0.05$.

Table no. 2 - Logistic regression results

\begin{tabular}{ccccccc}
\hline Independent variable & B & S.E. & Wald & df & Sig. & $\operatorname{Exp(B)}$ \\
\hline Marketing budget change & 0,702 & 0,195 & 12,974 & 1 & 0,000 & 2,018 \\
\hline Advertising budget change & 0,746 & 0,215 & 12,097 & 1 & 0,001 & 2,109 \\
\hline
\end{tabular}

The model explained $18 \%$ (based on Nagelkerke's $\mathrm{R}^{2}$ coefficient) of the variance in the positive or neutral effect of the crisis on the organisation and correctly classified $67.5 \%$ of cases. Nagelkerke's $\mathrm{R}^{2}$ coefficient is below $20 \%$ but considering that only one independent variable comprises the model predicting the effect of the crisis on organisation, it is acceptable. The increased marketing budget during the pandemic crisis is associated with an increased likelihood of a positive or neutral effect of the crisis on the organisation $(\beta=0.702$, $\mathrm{p}<0.05$ ). For each point increase on the marketing budget, the odds of having a positive or neutral effect of a crisis increase 2.018 times. 
Regarding the influence of the advertising budget's change during the pandemic crisis (first wave) on the effect of the pandemic crisis on the organisation, the logistic regression model is again statistically significant, $\chi^{2}(1)=15.061, \mathrm{p}<0.05$. The model explained $20 \%$ (based on Nagelkerke's $\mathrm{R}^{2}$ coefficient) of the variance in a positive or neutral effect of the crisis on the organisation and correctly classified $69.8 \%$ of cases. Increasing the advertising budget during the pandemic crisis is associated with an increased likelihood of a positive or neutral effect of a crisis on the organisation $(\beta=0.746, p<0.05)$. For each point increase on the advertising budget, the odds of having a positive or neutral effect of a crisis on the organisation increase 2.109 times. Consequently, the marketing and advertising budget's change during a crisis (pandemic or not) must be a priority and very well thought through decision.

\section{DISCUSSION}

The analysis of the research results revealed that demand, income, and expenditure decreased in most organisations during the first COVID-19 wave, compared to the time before the pandemics. After the first wave of COVID-19, demand and income slightly increased in most organisations, yet, on the contrary, during the second wave demand and income decreased a little, but to a less extent compared to the decrease during the first COVID-19 wave. Therefore, it suggests that after the first COVID-19 wave a big part of organisations adapted to the pandemic situation.

The other trend brought by the COVID-19 crisis and visible from the research results is the growth of the number of organisations using online sales channels (or making it more active) and a decrease in the number of organisations using only physical stores. Of course, first of all, this trend was influenced by the regulations of the government, but it can be seen that the trend is visible even when the regulations of the government are suspended. Hence, organisations increasingly use the benefits of e-commerce and this trend has triggered a growing need for specialised employees to work with online channels and social media.

Additionally, the role of the marketing manager in the context of strategic organisational decision-making and implementation during the COVID-19 crisis became more important as well as the COVID-19 crisis has influenced companies' marketing strategies. During the first COVID-19 wave, changes were related to the decreased advertising budget, decreased activities, reorganised communication channels, and the focus on e-commerce. Meanwhile, during the second COVID-19 wave, changes were related to the increased advertising budget (only for a small part of organisations), the more serious focus on e-commerce, positioning organisation's stability, or again the decreased advertising budget for some part of organisations; in cases, even no changes were employed as companies have been already adapted after the first wave. The decreased marketing or advertising budget during the pandemic crisis does not surprise as more than one third of respondents revealed that they do not follow global recommendations not to decrease the marketing budget during the crisis. But what is interesting so is the fact that the decrease in marketing or advertising budgets was more intense only during the first wave of COVID-19. Nevertheless, the research results revealed that the decrease in marketing or advertising budgets might have influenced the negative outcomes of the pandemic on the organisations' performance. The results revealed that for each point increase on the marketing or advertising budget, the odds of having a positive or neutral effect of the crisis on the organisation increase substantially. Hence, the marketing and advertising budget change during the crisis (pandemic or not) must be a priority and very well thought through decision. This is 
very important as more than a half of the companies have experienced the negative impact of the crisis on the organisations' performance. Consequently, this research is in alignment with the authors stating that organisations are cutting their marketing or advertising budgets during the crisis (Deleersnyder et al., 2009; Kang et al., 2020; Hunneman, 2020; Hoekstra and Leeflang, 2020), but actually, they should maintain or increase marketing or advertising spending during recessions (Deleersnyder et al., 2009; Lamey et al., 2012; Dekimpe and Deleersnyder, 2018), whether it is a financial or a pandemic crisis.

Regarding the change related to the marketing department, most of the organisations did not apply changes here. Those who did, indicated such reasons as the company's growth, a decrease in the marketing budget, or workload. Consequently, again this is related to the changes in the marketing budget. In the same aspect, the collaboration with external agencies/consultants is also related: nearly one-fourth of organisations decreased the number of orders when collaborating with external agencies/consultants because of the changed marketing budget. Despite the fact that most of the organisations have not changed their marketing departments, the COVID-19 crisis affected their marketing team's functions, namely: communication became more intense, fewer marketing functions were outsourced, they got more responsibility, there was a growing need for e-commerce. Thus, it could be stated that changed workloads, emotional state, and the general pandemic situation might have influenced employees' well-being. Nevertheless, the analysis of the research results revealed that most of the organisations are already considering post-crisis actions. These results are in alignment with the studies of the COVID-19 impact on marketing management in Lithuania during the first COVID-19 wave (European Marketing Agenda, 2021; Balčiūnienè, 2020), stating that the primary effect was a budget reduction in general and the main changes were made in online commerce. However, this research extends the results to the impact of COVID19 on marketing management in Lithuania over a wider period of time.

When compared to other countries, it could be seen that digitalisation is the Top 1 priority when considering the main effects of the COVID-19 pandemic on marketing operations in Europe (European Marketing Agenda, 2021), and the results of this research support this statement, indicating that the increased focus on digitalisation is likely to be the general trend in European organisations. Moreover, The Coronavirus on Advertising Report (2020) revealed that $89 \%$ of companies indicated that their advertising budgets were impacted by the pandemic. In Lithuania, as it has been revealed by the research results, more than $70 \%$ of organisations' advertising budgets were impacted by the pandemic. Therefore, it is obvious that the results again are similar across European organisations and the pandemic crisis more or less affected most of the organisations' marketing and advertising budgets. CMO Survey $(2020,2021)$ stated that the first wave of the COVID-19 pandemic did not change the outsourcing of the marketing landscape in the US. In Lithuania, more than $60 \%$ of organisations changed their collaboration with external agencies/consultants during the first COVID-19 wave mostly because of the marketing budget change. Moreover, CMO Survey $(2020,2021)$ stated that expected marketing hiring dropped to historic lows during the first wave, but in January of 2021 rebounded beyond the pre-pandemic levels in the US. In Lithuania, more than $70 \%$ of organisations reported that the structure of the marketing department did not change either during the COVID-19 waves. Finally, it could be stated that general and most evident trends induced by the COVID-19 pandemic across European organisations are digitalisation and the impact of the crisis on marketing and/or advertising budgets. Other marketing management aspects affected by the COVID-19 pandemic may slightly differ across European countries. 


\section{CONCLUSIONS}

The theoretical analysis revealed that the COVID-19 pandemic influenced marketing, and it had to search for new strategies how to adjust to new consumer behaviour patterns, the changed demand and supply. The pandemic period has dictated new decisions related to marketing strategy adjustment, search for marketing innovations, R\&D, new product development, pricing, marketing channel redesign, reconsideration of corporate social responsibility as a part of the marketing strategy, re-evaluation of marketing and advertising budgets, as well as communication.

The research results lead to a conclusion that even though most of the organisations' performance indicators decreased in many organisations during the first COVID-19 wave, compared to the time before the pandemics, yet after the first COVID-19 wave, a big part of organisations adapted to the pandemic situation.

The analysis of the research results allows to conclude that organisations increasingly take advantage of the benefits of e-commerce and there is an apparent decrease in the number of organisations using only physical stores. Thus, the assumption could be made that the COVID-19 pandemics will bring nearer to the paradigm shift in a business-consumer relationship.

The received results revealed that most of the organisations do not follow global recommendations not to decrease marketing or advertising budgets during the crisis, especially during the first wave of the COVID-19 pandemics. Nevertheless, a decrease in marketing or advertising budgets might have influenced the negative outcomes of the pandemic on the organisations' performance as for each point increase on the marketing or advertising budget, the odds of having a positive or neutral effect of a crisis on the organisation increase substantially. Therefore, the marketing and advertising budget change during a crisis (pandemic or not) must be a priority and very well thought through decision.

Based on the analysis of research results it could be stated that changed workloads, emotional state, and the general pandemic situation might have influenced employees' wellbeing. Moreover, the analysis results revealed that most of the organisations are already considering post-crisis actions, which is a positive sign for business.

The provided research results and recommendations are valuable for scientists as well as marketing practitioners. The provided insights will enable organisations to react appropriately to the crisis and perform suitable marketing actions. Moreover, the research results have indicated the changes which occurred in the marketing landscape, therefore, these findings create scientific value and provide a basis for further research.

\section{Acknowledgements}

Lithuanian Marketing Association (LIMA)

\section{ORCID}

Miglè Šontaitė-Petkevičienė (iD https://orcid.org/0000-0002-9101-6627

Asta Kyguolienė iD https://orcid.org/0000-0003-4204-2420

Viktorija Grigaliūnaite (iD https://orcid.org/0000-0001-8340-2993 


\section{References}

Abdelnour, A., Babbitz, T., and Moss, S., 2020. Pricing in a pandemic: navigating the COVID-19 crisis. from https://www.mckinsey.com/business-functions/marketing-and-sales/our-insights/pricing-ina-pandemic-navigating-the-covid-19-crisis

Aguilera, R., Rupp, D., Williams, C., and Ganapathi, J., 2007. Putting the S back in corporate social responsibility: A multilevel theory of social change in organizations. Academy of Management Review, 32(3), 836-863. http://dx.doi.org/10.5465/amr.2007.25275678

Ansari, B., and Ganjoo, M., 2020. Impact of Covid-19 on advertising: A perception study on the effects on print and broadcast media and consumer behavior. Purakala, 31(28), 52-62.

Balčiūnienè, R., 2020. COVID-19 krizė apkarpè rinkodaros išlaidas, tačiau sukūrè naujų galimybių. from https://www.vz.lt/rinkodara/2020/06/14/covid-19-krize-apkarpe-rinkodaros-islaidas-taciausukure-nauju-galimybiu

Bundy, J., Pfarrer, M. D., Short, C. E., and Coombs, W. T., 2016. Crisis and crisis management: Integration, interpretation, and research development. Journal of Management, 6, 1661-1692. http://dx.doi.org/10.1177/0149206316680030

Cankurtaran, P., and Beverland, M., 2020. Using design thinking to respond to crises: B2B lessons from the 2020 Covid-19 pandemic. Industrial Marketing Management, 88, 255-260. http://dx.doi.org/10.1016/j.indmarman.2020.05.030

CMO Survey, 2020. COVID-19 and the state of Marketing. from https://cmosurvey.org/results/specialcovid-19-edition-june-2020/

CMO Survey, 2021. The transformation of marketing: emerging digital, social and political trends. from https://cmosurvey.org/results/26th-edition-february-2021/

Crick, J. M., and Crick, D., 2020. Coopetition and COVID-19: Collaborative business to business marketing strategies in a pandemic crisis. Industrial Marketing Management, 88, 206-213. http://dx.doi.org/10.1016/j.indmarman.2020.05.016

Customer Engagement Report, 2000. Merkle Insights. from https://www.merkleinc.com/news-andevents/press-releases/2020/merkles-covid-19-customer-engagement-report-finds-52-marketers

Dekimpe, M. G., and Deleersnyder, B., 2018. Business cycle research in marketing: A review and research agenda. Journal of the Academy of Marketing Science, 46(1), 31-58. http://dx.doi.org/10.1007/s11747-017-0542-9

Deleersnyder, B., Dekimpe, M. G., Steenkamp, J. B., and Leeflang, P. S. H., 2009. The role of national culture in advertising's sensitivity to business cycles: An investigation across continents. JMR, Journal of Marketing Research, 46(5), 623-636. http://dx.doi.org/10.1509/jmkr.46.5.623

Deloitte, 2021. $2021 \quad$ Global Marketing $\quad$ Trends. from https://www2.deloitte.com/content/dam/Deloitte/br/Documents/strategy/Deloitte-GlobalMarketing-Trends-2021.pdf

Diallo, M. D., and Kaswengi, J., 2016. What drives store brand purchases during crisis period? Evidence from panel data in four product categories. International Journal of Retail \& Distribution Management, 44(3), 301-319. http://dx.doi.org/10.1108/IJRDM-02-2015-0020

Donthu, N., and Gustafsson, A., 2020. Effects of COVID-19 on business and research. Journal of Business reseach, 117, 284-289. http://dx.doi.org/10.1016/j.jbusres.2020.06.008

Edelman Trust Barometer, 2020. Special report: brand trust and the coronavirus pandemic. from https://www.edelman.com/research/covid-19-brand-trust-report

ETUI and ETUC, 2020. Benchmarking working Europe 2020. from https://www.etui.org/sites/default/files/2020-12/09\%20ETU\%20BM2020\%20FULL.pdf

Euromonitor International, 2020. How is COVID-19 affecting the TOP 10 global Consumer Trends 2020? . from https://go.euromonitor.com/webinar-ec-2020-covid-19-impact-on-gct.html

European Marketing Agenda, 2021. LiMA. from https://lima.lt/lt/apie-lima/naujienos/tarptautinesmarketingo-apklausos-gggf.html 
Falk, G., Carter, J. A., Nicchitta, I. A., Nyhof, E. C., and Romero, D. P., 2021. Unemployment rates during the COVID-19 pandemic: In brief Congressional Research Service (pp. 1-13).

Finsterwalder, J., and Kuppelwieser, V. G., 2020. Equilibrating resources and challenges during crises: A framework for service ecosystem well-being. Journal of Service Management, 31(6), 11071129. http://dx.doi.org/10.1108/JOSM-06-2020-0201

Foss, N. J., 2021. The impact of the COVID-19 pandemic on firm's organizational designs. Journal of Management Studies, 58(1), 268-272. http://dx.doi.org/10.1111/joms.12643

Global Technology Governance Report, 2020. Harnessing fourth industrial revolution technologies in a COVID-19 world. from http://www3.weforum.org/docs/WEF_Global_Technology_Governance_2020.pdf

Grewal, R., and Tansuhaj, P., 2001. Building organizational capabilities for managing economic crisis: The role of market orientation and strategic flexibility. Journal of Marketing, 65(2), 67-80. http://dx.doi.org/10.1509/jmkg.65.2.67.18259

Grundey, D., 2009. Branding strategies during economic crisis: Avoiding the erosion. Economics \& Sociology (Ternopil), 2(2), 9-22. http://dx.doi.org/10.14254/2071-789X.2009/2-2/1

Guillen, M. F., 2020. How businesses have successfully pivoted during the pandemic. Harvard Business Review, July.

Gulati, R. N. N., and Wohlgezogen, F., 2010. Roaring out of recession. Harvard Business Review: March Issue.

Hampson, D. P., and McGoldrick, P. J., 2013. A typology of adaptive shopping patterns in recession. Journal of Business Research, 66(7), 831-838. http://dx.doi.org/10.1016/j.jbusres.2011.06.008

He, H., and Harris, L., 2020. The impact of Covid-19 pandemic on corporate social responsibility and marketing philosophy. Journal of Business Research, 116, 176-182. http://dx.doi.org/10.1016/j.jbusres.2020.05.030

Hoekstra, J. C., and Leeflang, P. S. H., 2020. Marketing in the era COVID-19. Italian Journal of Marketing, 2020(4), 249-260. http://dx.doi.org/10.1007/s43039-020-00016-3

Hunneman, A., 2020. The do's and don'ts for marketing in a recession. Norwegian Business School. from https://www.bi.edu/research/business-review/articles/2020/05/the-dos-and-donts-formarketing-in-a-recession/

ILOSTAT, 2020. COVID-19 is driving up food prices all over the world. International Labour Organization. from https://ilostat.ilo.org/covid-19-is-driving-up-food-prices-all-over-the-world/

Kang, J., Diao, Z., and Zanini, M. T., 2020. Business to business marketing responses to COVID-19 crisis: a business process perspective. Marketing Intelligence \& Planning, ahead of print. http://dx.doi.org/10.1108/MIP-05-2020-0217

Kim, M., Roehl, W., and Lee, S. K., 2019. Effect of hotels' price discounts on performance recovery after a crisis. International Journal of Hospitality Management, 83, 74-82. http://dx.doi.org/10.1016/J.IJHM.2019.04.006

Lamey, L., Deleersnyder, B., Steenkamp, B., and Dekimpe, M., 2012. The effect of business-cycle fluctuations on private-label share: What has marketing conduct got to do with it? Journal of Marketing, 75(1), 1-19. http://dx.doi.org/10.1509/jm.09.0320

Manuel, T., and Herron, T. L., 2020. An ethical perspective of business CSR and the COVID-19 pandemic. Society and Business Review, 15(3), 235-253. http://dx.doi.org/10.1108/SBR-06-20200086

Mollenkopf, D. A., Ozanne, L. K., and Stolze, H. J., 2021. A transformative supply chain response to COVID-19. Journal of Service Management, 32(2), 190-202. http://dx.doi.org/10.1108/JOSM-052020-0143

Moon, J., Choe, Y., and Song, H., 2021. Determinant of consumers' online / offline shopping behaviours during the COVID-19 Pandemic. International Journal of Environmental Research and Public Health, 18(4), 1-15. http://dx.doi.org/10.3390/ijerph18041593

Morens, D. M., Folkers, G. K., and Fauci, A. S., 2009. What is a pandemic? The Journal of Infectious Diseases, 200(7), 1018-1021. http://dx.doi.org/10.1086/644537 
Naidoo, V., 2010. Firm survival through a crisis: The influence of market orientation, marketing innovation and business strategy. Industrial Marketing Management, 39, 1311-1320. http://dx.doi.org/10.1016/j.indmarman.2010.02.005

Narayandas, D., Hebbar, V., and Li, L., 2020. Lessons from Chinese companies' response to COVID19. Harvard Business Review, June.

Nielsen, 2020. Key consumer behavior thresholds identified as the coronavirus outbreak evolves. from https://nielseniq.com/global/en/insights/analysis/2020/key-consumer-behavior-thresholdsidentified-as-the-coronavirus-outbreak-evolves-2/

Obal, M., and Gao, T., 2020. Managing business relationships during a pandemic: Conducting a relationship audit and developing a path forward. Industrial Marketing Management, 88(1), 247254. http://dx.doi.org/10.1016/j.indmarman.2020.05.025

OECD, 2020. Exploitative pricing in the time of COVID-19. from https://www.oecd.org/competition/Exploitative-pricing-in-the-time-of-COVID-19.pdf

Qiu, W., Rutherford, S., Mao, A., and Chu, C., 2017. The Pandemic and its Impacts. Health, Culture and Society (Pittsburgh, Pa.), 9, 1-11. http://dx.doi.org/10.5195/hcs.2017.221

Sharma, P., 2020. Impact of COVID-19 on marketing strategy and expenditure. International Journal of Advanced Research, 8(9), 1475-1478. http://dx.doi.org/10.21474/IJAR01/11814

Shrivastava, P., 1993. Crisis theory/practice: Towards a sustainable future. Organization \& Environment, 7(1), 23-42. http://dx.doi.org/10.1177/108602669300700103

Srinivasan, R., Rangaswamy, A., and Lilien, G. L., 2005. Turning adversity into advantage: Does proactive marketing during a recession pay off? International Journal of Research in Marketing, 22(2), 109-125. http://dx.doi.org/10.1016/j.ijresmar.2004.05.002

The Coronavirus on Advertising Report, 2020. Advertiser perceptions. from https://www.advertiserperceptions.com/wp-content/uploads/2020/04/03.2020-CoronavirusEffect-on-Advertising-White-Paper-FINAL.pdf

Van Heerde, H. J., Gijsenberg, M. J., Dekimpe, M. G., and Steenkamp, J. B. E. M., 2013. Price and advertising effectiveness over the business cycle. JMR, Journal of Marketing Research, 50(2), 177-193. http://dx.doi.org/10.1509/jmr.10.0414

Wang, Y., Hong, A., Li, X., and Gao, J., 2020. Marketing innovations during a global crisis: A study of China firms' response to COVID-19. Journal of Business Research, 116(1), 214-220. http://dx.doi.org/10.1016/j.jbusres.2020.05.029

World Health Organization, 2021. WHO Coronavirus (Covid-19) Dashboard. from https://covid19.who.int/

\section{Copyright}

This article is an open access article distributed under the terms and conditions of the Creative Commons Attribution-NonCommercial-NoDerivatives 4.0 International License. 